\title{
FAKTOR YANG MEMPENGARUHI PENGGUNAAN FINANCIAL TECHNOLOGY LINKAJA SEBAGAI ALAT PEMBAYARAN ELEKTRONIK
}

\author{
Riana Mahfuroh ${ }^{* 1}$, Aditya Pandu Wicaksono ${ }^{2}$ \\ ${ }^{1,2}$ Program Studi Akuntansi, Fakultas Bisnis dan Ekonomika Universitas Islam Indonesia, Yogyakarta, \\ Indonesia \\ *e-mail: rianamahfuroh@uii.ac.id
}

\begin{abstract}
ABSTRAK
Akselerasi perkembangan teknologi digital membawa perubahan pada perilaku konsumen dalam melakukan transaksi keuangan. Perubahan preferensi transaksi keuangan dari offline menjadi online mendorong berkembangnya berbagai aplikasi dompet elektronik, salah satunya yaitu LinkAja. Penelitian ini bertujuan untuk mengamati intensi penggunaan LinkAja sebagai alat pembayaran elektronik. Kuesioner elektronik dibagikan kepada para pengguna aplikasi LinkAja untuk dianalisis. Seluruh kuesioner yang terisi dengan lengkap kemudian dianalisis dengan menggunakan SmartPLS. Penelitian ini mendukung teori Technology Acceptance Model (TAM). Perceived Usefulness dan Ease of Use terbukti secara positif mempengaruhi intensi penggunaan LinkAja. Selain itu, Ease of Use memberikan dukungan yang berarti terhadap Perceived Usefulness pengguna untuk menggunakan LinkAja. Hubungan Satisfaction secara positif berpengaruh terhadap Trust. Adapun temuan yang tidak berpengaruh secara signifikan perlu dilakukan investigasi lebih lanjut. Satisfied dan Trust tidak memiliki pengaruh yang signifikan terhadap Intention to Use. Sementara, Satisfied tidak memiliki asosiasi langsung terhadap intensi penggunaan LinkAja.
\end{abstract}

Kata Kunci: Dompet Elektronik, Pembayaran elektronik, TAM, Kepuasan, Kepercayaan

\section{ABSTRACT}

The acceleration of digital technology development has brought changes in consumer behavior in conducting financial transactions. The change in preferences for financial transactions from offline to online has encouraged the development of various electronic wallet applications, one of which is LinkAja. This study aims to observe the intention to use LinkAja as an electronic payment. Electronic questionnaires were distributed to LinkAja application users for analysis. All completed questionnaires were analyzed using SmartPLS. This study supports the Technology Acceptance Model (TAM) theory. Perceived Usefulness and Ease of Use are proven positively affect the intended use of LinkAja. In addition, Ease of Use provides significant support for Perceived Usefulness of users to use LinkAja. Satisfaction relationship positively affects trust. Furthermore, insignificant effect of findings need further investigation. Satisfied and Trust do not have a significant effect on Intention to Use. Meanwhile, the satisfied has no direct association with the intention to use of LinkAja.

Keywords: E-Wallet, E-Payment, TAM, Satisfaction, Trust 


\section{PENDAHULUAN}

Perkembangan teknologi digital mengalami akselerasi di era industri 4.0. Pengguna internet di Indonesia dari tahun ke tahun mengalami peningkatan. Berdasarkan riset dari lembaga pemerhati digital global We Are Social (2020) yang berkolaborasi dengan HootSuite, pengguna internet di Indonesia pada tahun 2020 sebanyak 175.4 juta pengguna. Pengguna internet ini mengalami peningkatan sebesar 17\% dibandingkan dengan tahun sebelumnya [1]. Meningkatnya penggunaan internet ini juga mempengaruhi perubahan pola perilaku konsumen dalam melakukan transaksi keuangan. Transaksi keuangan yang awalnya dilakukan secara offline (luar jaringan) berkembang menjadi transaksi online (dalam jaringan) [2]. Potensi pertumbuhan jasa layanan keuangan digital tersebut mendapat sambutan dari para penyedia jasa keuangan untuk mengembangkan aplikasi pembayaran elektronik.

Aplikasi pembayaran elektronik financial technology (fintech) yang berkembang saat ini diantaranya Go-Pay, OVO, LinkAja, dan DANA. Dari keempat aplikasi tersebut, LinkAja merupakan aplikasi yang terakhir diluncurkan. LinkAja merupakan transformasi dari gabungan dompet elektronik yang dimiliki oleh beberapa perusahaan Badan Usaha Milik Negara (BUMN) diantaranya PT Telekomunikasi Indonesia Tbk (T-Cash), PT Bank Mandiri Tbk (e-Cash), PT Bank Rakyat Indonesia Tbk (T-Bank), dan PT Bank Negara Indonesia Tbk (UnikQu). LinkAja dikembangkan oleh PT Fintek Karya Nusantara dan resmi diluncurkan oleh Kementerian BUMN pada 30 Juni 2019 [3].

Sebagai satu-satunya dompet elektronik milik pemerintah, LinkAja mendapat privilege khusus. Layanan yang diberikan oleh LinkAja terintegrasi dengan layanan-layanan Badan Usaha Milik Negara (BUMN). Berbagai kemudahan yang diberikan oleh LinkAja dapat meningkatkan persepsi pengguna mengani kemanfaatan aplikasi LinkAja. Pengguna dapat dengan mudah menempatkan uangnya pada aplikasi LinkAja dan dapat dengan mudah melakukan pembayaran produk, transfer uang, maupun melakukan tarik tunai. Selain itu, LinkAja juga menyediakan layanan khusus yang belum dimiliki oleh dompet elektronik lainnya yaitu LinkAja Syariah. LinkAja Syariah dirancang untuk memberikan pelayanan yang sesuai dengan syariat Islam yang bebas ribawi, gharar, maysir, tadlis, risywah, dan israf. Hal ini dapat memenuhi harapan pengguna yang ingin melakukan transaksi keuangan secara syariah. Terobosan-terobosan tersebut dilakukan dalam rangka memberikan pelayanan terbaik agar dapat meraih pangsa pasar yang tinggi. 
Hingga saat ini, terdapat 51 penyedia fintech yang telah memperoleh izin dari Bank Indonesia [4]. Semakin banyak penyedia fintech, maka persaingan menjadi semakin ketat. Perkembangan ini berdampak pada persaingan yang semakin kompetitif agar penyedia fintech dapat mempertahankan eksistensinya dengan cara memberikan layanan yang berkualitas. Berbagai fitur dan layanan ditawarkan oleh masing-masing penyedia. Perbedaan fitur dan layanan dapat mempengaruhi seseorang untuk menggunakan aplikasi [5]. Oleh karena itu, penting bagi penyedia fintech untuk mengidentifikasi hal-hal apa saja yang mempengaruhi penggunaan dompet elektronik di Indonesia agar dapat mengembangkan sistem sesuai dengan kebutuhan penggunanya.

Penelitian ini dikembangkan dari teori Technology Acceptance Model (TAM) yang ditemukan oleh Davis (1989). TAM pada awalnya dikembangkan untuk memprediksi perilaku individu dalam mengadopsi suatu teknologi informasi maupun sistem aplikasi yang baru. Model TAM dapat dikombinasikan dengan variabel eksternal yang dapat digunakan untuk memprediksi penggunaan sistem/teknologi. Model TAM merupakan adaptasi dari Theory of Reasoned Action [6]. TAM mengalami penyempurnaan, dimana TAM1 (final TAM) mengeluarkan konstruk attitude toward using karena tidak sepenuhnya memberikan pengaruh mediasi atas persepsi kegunaan terhadap intensi untuk menggunakan sistem/teknologi [7]. TAM1 mengamati cognitive response terhadap intention dengan memasukkan variabel eksternal. Niat penggunaan (intention to use) sistem/teknologi ditentukan oleh sikap untuk menggunakan. Dalam hal ini, sikap tercermin dua hal yaitu persepsi kegunaan (perceived usefulness) dan persepsi kemudahan penggunaan (perceived ease of use). Niat penggunaan ini pada akhirnya akan mempengaruhi seseorang untuk menggunakan sistem/teknologi dengan sesungguhnya (actual system use).

Penelitian ini dilakukan untuk mengidentifikasi faktor-faktor potensial yang mendorong seseorang untuk menggunakan sistem/teknologi (intention to use), sehingga penyedia fintech dapat memfokuskan upaya pada variabel yang secara signifikan mempengaruhi intention to use sistem/teknologi tersebut. Behavioral intention to use merupakan kecenderungan niat perilaku untuk menggunakan suatu teknologi atau tidak. Hal ini dapat dilihat dari sikap dan perhatian yang dicurahkan pada teknologi tersebut [6]. Intention to use merujuk pada tindakan yang akan dilakukan oleh pengguna, apakah akan menggunakan sistem/teknologi tersebut atau tidak. Tindakan ini merupakan manifestasi dari 
bagaimana seseorang mempersepsikan sistem/teknologi. Proses persepsi yang sebelumnya telah dilakukan oleh pengguna akan menghasilkan keputusan yang disebut dengan aksi.

Penelitian mengenai penggunaan alat pembayaran elektronik telah banyak diteliti. Kristiani \& Pambudi (2017) meneliti tentang penggunaan mobile banking pada mahasiswa di Jakarta dan menemukan bahwa persepsi kemudahan, persepsi kemanfaatan, tingkat keamanan, dan fitur layanan yang disediakan memiliki pengaruh terhadap penggunaan mobile banking di kalangan mahasiswa di Jakarta [5]. Seiring dengan berkembangan metode pembayaran elektronik, beberapa peneliti telah melakukan penelitian mengenai perilaku pengguna dalam menggunakan dompet elektronik di Indonesia. Febrilia, Pratiwi, \& Djatikusumo, 2020; Indrawati \& Putri, 2018; Azizah, Handayani, \& Azzahro, 2018; Megadewandanu, Suyoto, \& Pranowo, 2017; dan Nabila et al., 2018 meneliti mengenai intensi penggunaan dompet elektronik secara umum di Indonesia. Sedangkan Shaury (2019) meneliti mengenai pemosisian dompet elektronik di Indonesia. Penelitiannya menemukan bahwa setiap dompet elektronik memiliki karakteristik yang berbeda dan memiliki daya tarik yang berbeda terhadap penggunanya [8].

Berbeda dengan penelitian sebelumnya yang mengidentifikasi faktor penggunaan dompet elektronik secara umum, penelitian ini bertujuan untuk mengamati penggunaan sistem aplikasi yang lebih spesifik. Setiap sistem aplikasi memiliki karakteristik, fitur, dan layanan yang berbeda, sehingga dapat mempengaruhi keputusan seseorang untuk menggunakan sistem aplikasi tersebut [8] (Shaury, 2019). Penelitian ini dilakukan dengan menggunakan model final TAM (Davis \& Venkatesh, 1996) dengan memasukkan variabel eksternal yang dimodifikasi. TAM merupakan model yang sangat kuat untuk digunakan dalam memprediksi penggunaan teknologi informasi [9]. TAM secara konsisten terbukti dapat memprediksi perilaku penggunaan sistem/teknologi [10].

\section{METODE PENELITIAN}

Populasi penelitian ini meliputi seluruh pengguna aplikasi dompet elektronik LinkAja. Sampel penelitian dipilih menggunakan convenience sampling agar memberikan kemudahan bagi peneliti untuk menjangkau subyek yang akan diikutkan dalam penelitian dan memiliki kesesuaian dengan kriteria pada populasi penelitian [11]. Data yang digunakan merupakan data primer yang diambil secara langsung dari responden melalui kuesioner survei elektronik berupa google form. Item jawaban pada kuesioner ini disusun menggunakan skala likert 1-4. Instrumen yang telah disusun, terlebih dahulu diujikan melalui pilot tes yang dilakukan 
kepada 10 subyek untuk mendapatkan masukan. Kuesioner dari hasil pilot tes yang telah direvisi kemudian dibagikan kepada responden. Sebanyak 157 responden berpartisipasi pada penelitian ini.

Data yang telah terkumpul selanjutnya dianalisis menggunakan pendekatan Partial Least Square (PLS) dengan bantuan aplikasi SmartPLS 3 [12]. Tahap evaluasi pada PLSSEM terdiri dari dua tahapan yaitu uji measurement models (outer model) dan uji structural model (inner model) [13]. Pada tahap uji kelayakan model measurement models, tahap pertama yang dilakukan adalah menguji validitas dengan cara menganalisis discriminant validity dan convergent validity. Discriminant validity mencerminkan tingkat ketidaksesuaian alat ukur dengan konsep yang menjelaskan keberadaan atribut-atribut dari variabel tersebut. Sedangkan convergent validity mencerminkan tingkat kesesuaian alat ukur dengan konsep yang menjelaskan keberadaan atribut-atribut variabel tersebut. Selain itu, pengujian lain yaitu dengan menganalisis Average Variance Extracted (AVE). Cross loading indicators yang memiliki nilai diatas 0.70 dengan nilai AVE 0.50 dapat dikatakan bahwa item memiliki tingkat validitas yang dapat diterima. Uji validitas dilanjutkan dengan menganalisis discriminant validity. Pada umumnya, nilai discriminant validity yang lebih tinggi mencerminkan tingkat validitas yang semakin tinggi, akan tetapi jika nilai melebihi 0.95 hal ini akan menjadi masalah [13].

Setelah berhasil melewati pengujian measurement model, tahap selanjutnya yaitu melakukan pengujian atas structural model. Pengujian structural model dilakukan untuk melihat hubungan antar variabel dengan boothstrapping technique. Boothstrapping akan menghasilkan nilai koefisien dan loading factor yang dianalisis lebih lanjut untuk melihat signifikansi hubungan dari masing-masing variabel. Jika p-value bernilai positif dan kurang dari 0.05 maka variabel tersebut memiliki pengaruh hubungan yang positif. Tingkat signifikansi dilihat dari nilai t-statistics. Jika nilai t-statistics lebih besar dari nilai t-table, maka hubungan variabel tersebut memiliki pengaruh yang signifikan. 


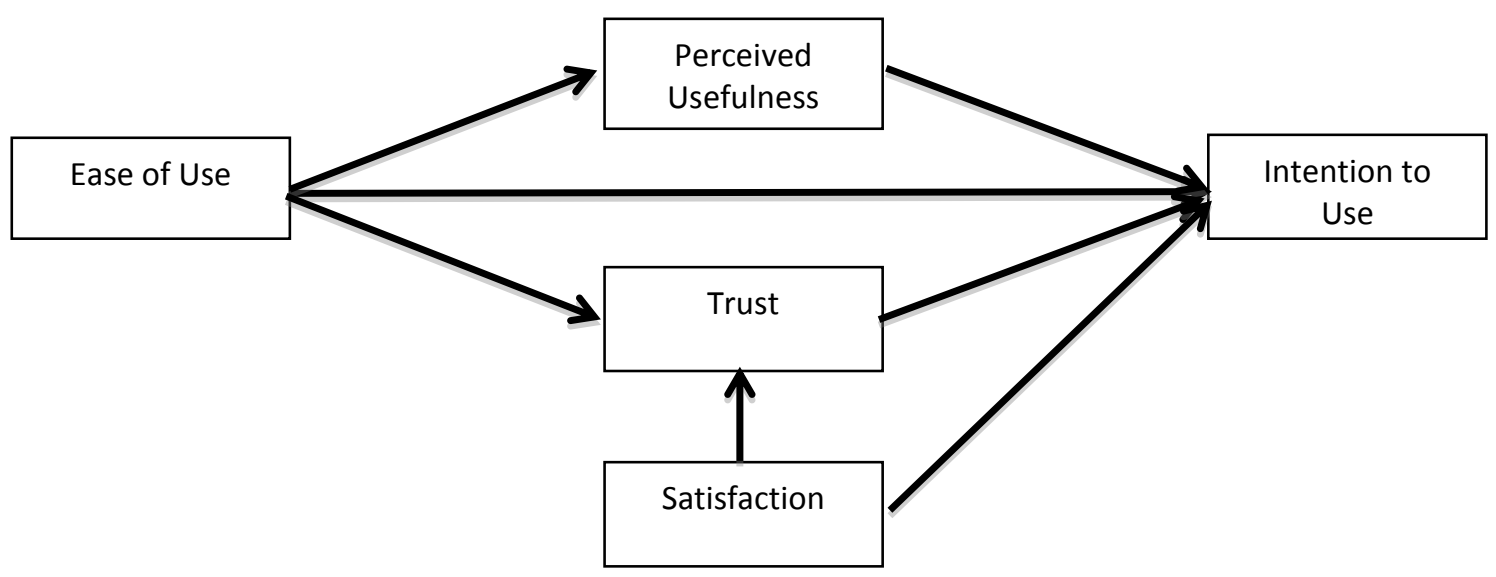

\section{Gambar 1. Model Penelitian}

Variabel dalam penelitian ini diadopsi dari teori Technology Acceptance Model (TAM) [6]. Model TAM Davis merupakan adaptasi dari Theory of Reasoned Action. TAM mengalami penyempurnaan, dimana TAM1 (final TAM) yang dikembangkan oleh Davis \& Venkatesh, (1996) mengeluarkan konstruk attitude toward using karena tidak sepenuhnya memberikan pengaruh mediasi atas persepsi kegunaan terhadap intensi untuk menggunakan sistem/teknologi. TAM1 mengamati cognitive response terhadap intention dengan memasukkan variabel eksternal. Niat penggunaan (intention to use) sistem/teknologi ditentukan oleh sikap untuk menggunakan. Dalam hal ini, sikap tercermin dua hal yaitu persepsi kegunaan (perceived usefulness) dan persepsi kemudahan penggunaan (perceived ease of use). Niat penggunaan ini pada akhirnya akan mempengaruhi seseorang untuk menggunakan sistem/teknologi dengan sesungguhnya (actual system use) [7]. Gambar 1 merupakan model penelitian dan Tabel 1 menunjukkan definisi operasional variabel yang diteliti pada penelitian ini.

Tabel 1. Definisi Operasional Variabel

\begin{tabular}{|c|c|c|c|}
\hline No & Variable & Definisi & Indikator \\
\hline 1 & Ease of use & $\begin{array}{l}\text { Ease of use dalam TAM didefinisikan } \\
\text { sebagai sejauhmana seseorang } \\
\text { menganggap bahwa ketika seseorang } \\
\text { menggunakan sistem/teknologi } \\
\text { terbebas dari usaha yang rumit [6]. Hal } \\
\text { ini mencerminkan kemudahan layanan } \\
\text { yang diberikan oleh penyedia dompet } \\
\text { elektronik. [14]. }\end{array}$ & $\begin{array}{l}\text { 1. E-wallet mudah dipelajari } \\
\text { 2. E-wallet mudah digunakan } \\
\text { 3. E-wallet sesuai harapan saya }\end{array}$ \\
\hline 2 & $\begin{array}{l}\text { Perceived } \\
\text { Usefulness }\end{array}$ & $\begin{array}{l}\text { Perceived usefulness merupakan } \\
\text { sejauhmana seseorang menganggap } \\
\text { bahwa penggunaan sistem/teknologi }\end{array}$ & $\begin{array}{l}\text { 1. E-wallet membantu dalam } \\
\text { pembayaran transaksi keuangan } \\
\text { 2. E-wallet meningkatkan efektivitas }\end{array}$ \\
\hline
\end{tabular}




\begin{tabular}{|c|c|c|c|}
\hline & & $\begin{array}{l}\text { dapat meningkatkan kinerjanya. } \\
\text { Dengan kata lain bahwa penggunaan } \\
\text { sistem/teknologi bermanfaat bagi } \\
\text { penggunanya [6]. }\end{array}$ & $\begin{array}{l}\text { pembayaran } \\
\text { 3. E-wallet bermanfaat dalam } \\
\text { pembayaran transaksi } \\
\text { 4. Penggunaan aplikasi e-wallet }\end{array}$ \\
\hline 3 & Trust & $\begin{array}{l}\text { Trust merupakan tingkat } \begin{array}{l}\text { kesediaan } \\
\text { mengerima }\end{array} \\
\text { ketidakpastian untuk } \\
\text { keyakinannya bahwa sistem/teknologi } \\
\text { dapat memenuhi keinginannya [15], } \\
\text { [16]. }\end{array}$ & $\begin{array}{l}\text { 1. E-wallet dapat menjaga } \\
\text { kerahasiaan data saya } \\
\text { 2. E-wallet selalu berusaha menjaga } \\
\text { komitmen dan kepercayaan } \\
\text { 3. E-wallet selalu berusaha } \\
\text { memenuhi kebutuhan saya } \\
\text { 4. E-wallet selalu menjalankan tugas } \\
\text { dengan sebaik-baiknya }\end{array}$ \\
\hline 4 & Satisfaction & $\begin{array}{l}\text { Kepuasan (satisfaction) } \\
\text { menggambarkan semua perasaan yang } \\
\text { dibangun atas interaksi yang dengan } \\
\text { penyedia layanan [17]. Tingkat } \\
\text { kepuasan dalam bertransaksi dapat } \\
\text { menjadi indikator penentu perilaku di } \\
\text { masa datang [17]. }\end{array}$ & $\begin{array}{l}\text { 1. Saya puas dengan pengalaman } \\
\text { penggunaan e-wallet } \\
\text { 2. Saya frustasi dengan pengalaman } \\
\text { penggunaan e-wallet } \\
\text { 3. Secara keseluruhan saya puas } \\
\text { 4. Secara keseluruhan saya tidak } \\
\text { puas }\end{array}$ \\
\hline 5 & $\begin{array}{l}\text { Intention } \\
\text { Use }\end{array}$ & $\begin{array}{l}\text { Intention to use merujuk pada tindakan } \\
\text { yang akan dilakukan oleh pengguna, } \\
\text { apakah akan menggunakan } \\
\text { sistem/teknologi tersebut atau tidak } \\
{[6] .}\end{array}$ & $\begin{array}{l}\text { 1. Saya akan menggunakan e-wallet } \\
\text { 2. Saya sangat mungkin } \\
\text { menggunakan e-wallet } \\
\text { 3. Saya bermaksud menggunakan e- } \\
\text { wallet di masa yang akan datang }\end{array}$ \\
\hline
\end{tabular}

\section{HASIL DAN PEMBAHASAN}

Data yang berhasil dikumpulkan pada penelitian ini sebanyak 157 responden. Data tersebut kemudian di screening untuk melihat apakah seluruh data diisi secara lengkap dan dapat diikutsertakan dalam penelitian ini. Adapun data yang diisi secara lengkap dan diikutkan dalam penelitian ini sebanyak 156 responden. Responden yang berpartisipasi dalam penelitian ini terdiri dari $50.6 \%$ laki-laki dan $49.4 \%$ perempuan dengan mayoritas usia pada rentang 16-20 tahun. Hal ini menunjukkan bahwa usia remaja memiliki antusias yang cukup tinggi dalam pemanfaatan teknologi. Adapun tujuan penggunaan LinkAja didominasi untuk melakukan pembayaran barang/belanja.

\section{Measurement Model}

Pengujian measurement model yang pertama yaitu melakukan uji validitas. Uji validitas dilakukan dengan menganalisis discriminant validity dan convergent validity. Penilaian discriminant validity menggunakan kriteria cross loading dari [18]. Indikator dengan cross loading di bawah 0.70 tidak diikutkan dalam penelitian. Selain itu, sebagai alternatif untuk memastikan discriminant validity, peneliti menganalisis rasio HTMT [19]. HTMT yang 
disajikan pada Tabel 2 menunjukkan bahwa seluruh konstruk memiliki rasio HTMT di bawah 0.9. Hal ini berarti bahwa kriteria uji discriminant validity terpenuhi.

Tabel 2. Hasil Uji Discriminant Validity Heteroit-monotrait

\begin{tabular}{cccccc}
\hline & EOU & ITU & PUS & SAT & TRS \\
\hline EOU & & & & & \\
ITU & 0.783 & & & & \\
PUS & 0.778 & 0.801 & & & \\
SAT & 0.746 & 0.724 & 0.779 & & \\
TRS & 0.528 & 0.639 & 0.631 & 0.639 & \\
\hline
\end{tabular}

Sumber: Data Diolah 2020

Uji convergent validity dilakukan dengan menganalisis AVE. Validitas konvergen dianggap sudah cukup memadai jika memiliki nilai AVE paling rendah 0.50. Tabel 3 menunjukkan bahwa nilai AVE untuk setiap konstruk telah melebihi 0.50 yang berarti bahwa seluruh item telah memenuhi syarat convergent validity. Setelah uji validitas, pengujian dilanjutkan dengan menguji konsistensi internal atau reliabilitas. Suatu konstruk dinilai memenuhi kriteria konsistensi internal jika memiliki nilai CA maupun CR lebih besar atau sama dengan 0.7, meskipun 0.6 masih dapat diterima [13]. Pada Tabel 2 menunjukkan bahwa seluruh item memiliki nilai CA di atas 0.7 dan nilai CR di atas 0.8. Dengan kata lain bahwa seluruh item telah memenuhi kriteria uji reliabilitas.

Tabel 3. Hasil Pengujian Measurement Models

\begin{tabular}{|c|c|c|c|c|}
\hline & Indikator & Loading & AVE & $\mathbf{C R}$ \\
\hline \multirow{3}{*}{$\begin{array}{l}\text { Perceived } \\
\text { Ease of } \\
\text { Use (EOU) }\end{array}$} & E-wallet mudah dipelajari & 0.909 & \multirow{3}{*}{0.824} & \multirow{3}{*}{0.934} \\
\hline & E-wallet mudah digunakan & 0.932 & & \\
\hline & E-wallet sesuai harapan saya & 0.882 & & \\
\hline \multirow{3}{*}{$\begin{array}{l}\text { Intention to } \\
\text { Use (ITU) }\end{array}$} & Saya akan menggunakan e-wallet & 0.863 & \multirow{3}{*}{0.682} & \multirow{3}{*}{0.865} \\
\hline & Saya sangat mungkin menggunakan e-wallet & 0.871 & & \\
\hline & $\begin{array}{l}\text { Saya bermaksud menggunakan e-wallet di } \\
\text { masa yang akan datang }\end{array}$ & 0.736 & & \\
\hline \multirow{4}{*}{$\begin{array}{l}\text { Perceived } \\
\text { Usefulness } \\
\text { (PUS) }\end{array}$} & $\begin{array}{l}\text { E-wallet membantu dalam pembayaran } \\
\text { transaksi keuangan }\end{array}$ & 0.918 & \multirow{4}{*}{0.707} & \multirow{4}{*}{0.903} \\
\hline & $\begin{array}{l}\text { E-wallet meningkatkan efektivitas } \\
\text { pembayaran }\end{array}$ & 0.904 & & \\
\hline & $\begin{array}{l}\text { E-wallet bermanfaat dalam pembayaran } \\
\text { transaksi }\end{array}$ & 0.925 & & \\
\hline & Penggunaan aplikasi e-wallet & 0.559 & & \\
\hline $\begin{array}{l}\text { Satisfaction } \\
\text { (SAT) }\end{array}$ & $\begin{array}{l}\text { Saya puas dengan pengalaman penggunaan } \\
\text { e-wallet }\end{array}$ & 0.837 & 0.623 & 0.868 \\
\hline
\end{tabular}




\begin{tabular}{|c|c|c|c|c|}
\hline & $\begin{array}{l}\text { Saya frustasi dengan pengalaman } \\
\text { penggunaan e-wallet }\end{array}$ & 0.71 & & \\
\hline & Secara keseluruhan saya puas & 0.865 & & \\
\hline & Secara keseluruhan saya tidak puas & 0.735 & & \\
\hline \multirow{4}{*}{$\begin{array}{l}\text { Trust } \\
\text { (TRS) }\end{array}$} & $\begin{array}{l}\text { E-wallet dapat menjaga kerahasiaan data } \\
\text { saya }\end{array}$ & 0.844 & \multirow{4}{*}{0.702} & \multirow{4}{*}{0.904} \\
\hline & $\begin{array}{l}\text { E-wallet selalu berusaha menjaga komitmen } \\
\text { dan kepercayaan }\end{array}$ & 0.888 & & \\
\hline & $\begin{array}{l}\text { E-wallet selalu berusaha memenuhi } \\
\text { kebutuhan saya }\end{array}$ & 0.761 & & \\
\hline & $\begin{array}{l}\text { E-wallet selalu menjalankan tugas dengan } \\
\text { sebaik-baiknya }\end{array}$ & 0.855 & & \\
\hline
\end{tabular}

Sumber: Data Diolah 2020

\section{Structural Model}

Pada uji structural model, peneliti menggunakan boothstrapping technique untuk menguji signifikansi koefisien. Hubungan antara variabel independen dan variabel dependen ditunjukkan dari P-Values yang memiliki nilai positif $<0.05$ menunjukkan bahwa variabel tersebut memiliki pengaruh yang positif. Sedangkan tingkat signifikansi ditunjukkan dari tstatistics $>$ t-table.

Tabel 4. Hasil Uji Hipotesis

\begin{tabular}{lcccc}
\hline & $\begin{array}{c}\text { Original } \\
\text { Sample }(\mathbf{O})\end{array}$ & $\begin{array}{c}\text { T Statistics } \\
(\mid \mathbf{O} / \text { STDEV } \mid)\end{array}$ & $\begin{array}{c}\text { P } \\
\text { Values }\end{array}$ & Hasil \\
\hline EOU -> ITU & 0.282 & 3.184 & 0.002 & Signifikan \\
EOU -> PUS & 0.69 & 13.063 & 0 & Signifikan \\
EOU -> TRS & 0.167 & 2.52 & 0.012 & Signifikan \\
PUS -> ITU & 0.314 & 3.592 & 0 & Signifikan \\
SAT -> ITU & 0.124 & 1.539 & 0.124 & Tidak Berpengaruh \\
SAT -> TRS & 0.452 & 6.413 & 0 & Signifikan \\
TRS -> ITU & 0.155 & 2.16 & 0.031 & Tidak Signifikan \\
\hline
\end{tabular}

T-table $=2.365$

Sumber: Data Diolah 2020

Perceived of usefulness memiliki pengaruh paling tinggi terhadap intensi penggunaan dompet elektronik LinkAja. Temuan ini sama dengan penelitian mengenai adopsi $e$ commerce yang juga menemukan bahwa perceived usefulness merupakan pemrediksi terkuat pada intention to use e-commerce [9]. Perceived of usefulness memiliki hubungan yang positif artinya ketika pengguna memiliki persepsi bahwa aplikasi LinkAja memberikan manfaat untuk mereka, maka pengguna akan tergerak untuk terus menggunakan aplikasi tersebut. 
Persepsi kegunaan merupakan variabel yang memiliki pengaruh terbesar terhadap intensi penggunaan LinkAja. Aplikasi LinkAja menawarkan berbagai layanan yang sangat beragam, hal ini dipersepsikan oleh responden dapat meningkatkan efektivitas dalam melakukan transaksi. Demikian juga variabel ease of use memberikan pengaruh positif dan signifikan terhadap intensi penggunaan LinkAja. Seseorang akan mengadopsi sistem/teknologi berdasarkan pertimbangan yang rasional. Ease of use dalam TAM didefinisikan sebagai sejauhmana seseorang menganggap bahwa ketika seseorang menggunakan sistem/teknologi terbebas dari usaha yang rumit [20]. Pengguna merasa bahwa kemudahan untuk mengoperasikan sebuah aplikasi akan mendorong mereka untuk menggunakan aplikasi tersebut dalam kehidupan sehari-hari. Temuan ini secara tidak langsung memberikan dukungan pada penelitian sebelumnya [10], [20], [21].

Ease of use menunjukkan pengaruh yang positif dan signifikan terhadap perceived of usefulness. Secara tidak langsung, temuan ini mendukung penelitian-penelitian sebelumnya bahwa ease of use memberikan kontribusi terhadap perilaku pengguna untuk menggunakan suatu sistem elektronik, yang disalurkan melalui persepsi kegunaan yang dirasakan oleh pengguna [22]. Ketika pengguna memiliki pengalaman menggunakan aplikasi secara mudah, maka akan meningkatkan persepsi pengguna mengenai manfaat menggunakan aplikasi tersebut. Peneliti juga mendapatkan temuan unik bahwa ease of use memiliki pengaruh positif dan signifikan terhadap trust. Hal ini menunjukkan bahwa kemudahan penggunaan aplikasi LinkAja dapat meningkatkan kepercayaan bagi para penggunanya. Temuan mendukung penelitian terdahulu yang dilakukan oleh [23], [24], [25], [26].

Pengujian variabel satisfaction menunjukkan bahwa satisfaction memiliki hubungan yang positif dan signifikan terhadap trust pada penggunaan LinkAja. Ketika pengguna merasa puas terhadap informasi mengenai aplikasi LinkAja maka hal tersebut akan meningkatkan kepercayaan pengguna untuk menggunakan aplikasi LinkAja. Meskipun satisfaction menunjukkan pengaruh yang signifikan terhadap trust, satisfaction tidak memiliki pengaruh terhadap intensi penggunaan LinkAja. Hal ini sejalan dengan penelitian Dabholkar dan Sheng yang menemukan bahwa satisfaction terhadap online recommendations agents tidak memberikan pengaruh terhadap intensi konsumen untuk membeli suatu produk [24]. Meskipun satisfaction tidak memberi pengaruh terhadap intention to use, akan tetapi penelitian ini menemukan bahwa satisfaction memiliki pengaruh tidak langsung terhadap 
trust. Hal ini sangat berarti dalam rangka memberikan dukungan terhadap literatur berkaitan dengan satisfaction.

\section{KESIMPULAN}

Penelitian ini menganalisis penerimaan masyarakat terhadap penggunaan aplikasi dompet elektronik LinkAja sebagai alat pembayaran elektronik dengan menggunakan TAM yang dikembangkan oleh Davis [6]. Penelitian ini menunjukkan bahwa model TAM yang banyak digunakan untuk menganalisis tingkat penerimaan teknologi baru, merupakan model yang handal. Hal ini dapat dilihat dari hasil uji hipotesis yang menunjukkan bahwa seluruh variabel TAM memiliki pengaruh yang positif dan signifikan. Variabel trust terhadap intensi penggunaan LinkAja dan satisfied terhadap trust yang disematkan pada penelitian ini memiliki pengaruh yang tidak signifikan. Sementara, variabel kepercayaan akan informasi/penggunaan awal aplikasi terhadap intensi penggunaan LinkAja tidak memiliki pengaruh apapun. Hal ini selanjutnya perlu dilakukan investigasi lebih lanjut. Penelitian ini memiliki implikasi bagi para penyedia fintech untuk menyediakan aplikasi dompet elektronik yang dapat dengan mudah dioperasikan, baik dilihat dari tampilan (user interface) maupun kemudahan dalam melakukan transaksi. Hal tersebut dapat meningkatkan persepsi kemanfaatan dan memberikan pengaruh bagi para pengguna untuk meningkatkan intensi penggunaan aplikasi dompet elektronik. Selain itu, penyedia fintech juga perlu memfokuskan pada hal-hal yang dapat mengurangi minat pengguna untuk menggunakan aplikasi agar tidak menimbulkan kerugian bagi perusahaan.

\section{SARAN}

Penelitian ini dilakukan dengan menyebarkan kuesioner elektronik kepada pengguna LinkAja. Responden yang berpartisipasi dalam penelitian ini memiliki rentang usia dan tingkat pendidikan yang beragam. Keberagaman sampel dapat menjadi nilai tambah yang dapat mencerminkan kondisi keberagaman pengguna LinkAja yang sesungguhnya. Meskipun demikian, penelitian ini memiliki kelemahan yaitu jumlah sampel yang terbatas. Diharapkan penelitian selanjutnya dapat mengumpulkan dan menganalisis data yang lebih banyak agar bisa mendapatkan hasil yang lebih baik. Selain itu, penelitian selanjutnya juga dapat dilakukan dengan menambahkan faktor-faktor pemoderasi lainnya seperti tingkat pendidikan, tingkat usia, dan gender untuk menganalisis lebih dalam pengaruh moderasi dalam penelitian. 


\section{DAFTAR PUSTAKA}

[1] We Are Social, "Global Digital Reports 2020," 2020. [Online]. Available: https://wearesocial.com/digital-2020.

[2] V. Halttunen, Consumer Behavior in Digital Era General Aspects and Findings of Empirical Studies on Digital Music with a Retrospective Discussion. 2016.

[3] Y. A. Rahayu, "Fakta Seputar LinkAja, Dompet Digital Milik BUMN," liputan6.com, 2019. https://www.liputan6.com/bisnis/read/3901278/fakta-seputar-linkaja-dompetdigital-milik-bumn.

[4] Bank Indonesia, "Daftar Penyelenggara Uang Elektronik yang Telah Memperoleh Izin dari Bank Indonesia," 2020. [Online]. Available: https://www.bi.go.id/id/sistempembayaran/informasi-perizinan/uang-elektronik/penyelenggaraberizin/Contents/Default.aspx.

[5] M. L. Kristiani and R. Pambudi, "Analisis Pengaruh Persepsi Kemudahan, Persepsi Kemanfaatan, Persepsi Tingkat Keamanan, dan Fitur Layanan Terhadap Penggunaan Mobile Banking pada Mahasiswa Di DKI Jakarta," J. Akunt., vol. 11, no. 1, pp. 50-67, 2017, doi: 10.1017/CBO9781107415324.004.

[6] F. D. Davis, "Perceived usefulness, perceived ease of use, and user acceptance of information technology," MIS Q. Manag. Inf. Syst., vol. 13, no. 3, pp. 319-339, 1989, doi: $10.2307 / 249008$.

[7] F. D. Davis and V. Venkatesh, "A critical assessment of potential measurement biases in the technology acceptance model: Three experiments," Int. J. Hum. Comput. Stud., vol. 45, no. 1, pp. 19-45, 1996, doi: 10.1006/ijhc.1996.0040.

[8] S. Shaury, "Analisis Positioning E-Wallet Berdasarkan Perceptual Mapping," Seiko J. Manag. Bus., vol. 3, no. 1, pp. 187-193, 2019, doi: https://doi.org/10.37531/sejaman.v3i1.531.

[9] P. A. Pavlou, "Consumer Acceptance of Electronic Commerce: Integrating Trust and Risk with the Technology Acceptance Model," Int. J. Electron. Commer., vol. 7, no. 3, pp. 69-103, 2003.

[10] D. Gefen, E. Karahannad, and D. W. Straub, "Trust and TAM in Online Shopping: An Integrated Model," MIS Q., vol. 27, no. 1, pp. 51-90, 2003, doi: 10.1021/es60170a601.

[11] I. Etikan, "Comparison of Convenience Sampling and Purposive Sampling," Am. J. Theor. Appl. Stat., vol. 5, no. 1, p. 1, 2016, doi: 10.11648/j.ajtas.20160501.11.

[12] C. M. Ringle, S. Wende, and J. M. Becker, "SmartPLS 3." SmartPLS GmbH, Beonningstedt, 2015.

[13] J. F. Hair, J. J. Risher, M. Sarstedt, and C. M. Ringle, "When to use and how to report the results of PLS-SEM," Eur. Bus. Rev., vol. 31, no. 1, pp. 2-24, 2019, doi: 10.1108/EBR-11-2018-0203. 
[14] P. G. Schierz, O. Schilke, and B. W. Wirtz, "Understanding consumer acceptance of mobile payment services: An empirical analysis," Electron. Commer. Res. Appl., vol. 9, no. 3, pp. 209-216, 2010, doi: 10.1016/j.elerap.2009.07.005.

[15] D. M. Rousseau, S. B. Sitkin, R. S. Burt, C. Camerer, D. M. Rousseau, and R. S. Burt, "Not so Different after All: A Cross-Discipline View of Trust," Acad. Manag. Rev., vol. 23, no. 3, pp. 393-404, 1998.

[16] P. A. Pavlou, A. G. Anderson, H. Liang, and Y. Xue, "Understanding and Mitigating Uncertainty in Online Exchange Relationships: A Principal-Agent Perspective 1 gating uncertainty perceptions, and extending the principal-agent perspective are discussed," Underst. Mitigating Uncertain. MIS Q., vol. 31, no. 1, pp. 105-136, 2007.

[17] M. Zviran and Z. Erlich, "Measuring IS User Satisfaction: Review and Implications," Commun. Assoc. Inf. Syst., vol. 12, no. July, 2003, doi: 10.17705/1cais.01205.

[18] C. Fornell and D. F. Larcker, "Evaluating Structural Equation Models with Unobservable Variables and Measurement Error," J. Mark. Res., vol. XVIII, no. 1, pp. 39-50, 1981, doi: 10.20546/ijcrar.2016.409.006.

[19] J. Henseler, C. M. Ringle, and M. Sarstedt, "A new criterion for assessing discriminant validity in variance-based structural equation modeling," J. Acad. Mark. Sci., vol. 43, no. 1, pp. 115-135, 2015, doi: 10.1007/s11747-014-0403-8.

[20] M. Nabila, B. Purwandari, B. A. A. Nazief, D. A. Chalid, S. S. Wibowo, and I. Solichah, "Financial Technology Acceptance Factors of Electronic Wallet and Digital Cash in Indonesia," 2018 Int. Conf. Inf. Technol. Syst. Innov. ICITSI 2018 - Proc., pp. 284-289, 2018, doi: 10.1109/ICITSI.2018.8696091.

[21] A. Taufan and R. T. Yuwono, "Analysis of Factors That Affect Intention to Use eWallet through the Technology Acceptance Model Approach ( Case Study: GO-PAY )," Int. J. Sci. Res., vol. 8, no. 7, pp. 413-419, 2019.

[22] R. Henderson and M. J. Divett, "Perceived usefulness, ease of use and electronic supermarket use," Int. J. Hum. Comput. Stud., vol. 59, no. 3, pp. 383-395, 2003, doi: 10.1016/S1071-5819(03)00079-X.

[23] V. S. Chau and L. W. L. C. Ngai, "The youth market for internet banking services: Perceptions, attitude and behaviour," J. Serv. Mark., vol. 24, no. 1, pp. 42-60, 2010, doi: 10.1108/08876041011017880.

[24] P. A. Dabholkar and X. Sheng, "Consumer participation in using online recommendation agents: Effects on satisfaction, trust, and purchase intentions," Serv. Ind. J., vol. 32, no. 9, pp. 1433-1449, 2012, doi: 10.1080/02642069.2011.624596.

[25] A. Dehghan, P. Arjomand, A. Nayyeri, and M. Tabatabaey, "Offering a Conceptual Model of Technology Acceptance in e-Banking Based on the Customers' Satisfaction and Trust," Comput. Sci. Converg. (CSA 2011 WCC 2011 Proceedings), no. July, pp. 415-424, 2012, doi: 10.1007/978-94-007-2792-2. 
Jurnal Ilmiah Akuntansi Manajemen Volume 3 Nomor 2 - November 2020

ISSN (print): 2598-0696, ISSN (online): 2684-9283

DOI: $10.35326 /$ jiam.v3i2

[26] A. Priyono, "Analisis Pengaruh Trust dan Risk dalam Penerimaan Teknologi Dompet Elektronik Go-Pay,” J. Siasat Bisnis, vol. 21, no. 1, pp. 88-106, 2017. 